\title{
A educação das famílias pobres como estratégia política para o atendimento das crianças de 0 - 3 anos: uma análise do Programa Família Brasileira Fortalecida
}

\begin{abstract}
Rosânia Campos * e Roselane Fátima Campos **
Resumo: Este artigo tem como objetivo analisar o Programa Família Brasileira Fortalecida, patrocinado pelo Unicef e adotado pelo governo brasileiro como estratégia para ampliar a oferta de atendimento para crianças de $0-3$ anos. Esse programa encontra-se fortemente vinculado às orientaçôes produzidas por organismos multilaterais, tais como Unesco e Unicef, ratificadas nos diversos fóruns que reúnem governantes da América Latina e Caribe (OEA, OEI). O programa brasileiro sustenta-se em um conjunto de concepções e recomendações destinadas diretamente às famílias que passam a ser mediadoras na educação das crianças. Constatamos que, por meio desse programa, procura-se imprimir novas normas de conduta, administrando e disciplinando as práticas e as estratégias socializadoras das famílias pobres, transformando o espaço familiar em um espaço pedagogicamente orientado. O Programa visa ainda à administração da pobreza, diminuindo as disparidades sociais e à promoção de um ambiente de educabilidade familiar, considerado como essencial para o posterior sucesso escolar da criança.
\end{abstract}

Palavras-chave: educação infantil; políticas educacionais; educação das famílias.

\section{Education of poor families as a political trategy for assistance to children aged from 0 to 3: an analysis of the Brazilian Family Strengthening Program}

Abstract: This article aims to analyze the Brazilian Family Strengthening Program, sponsored by UNICEF and adopted by the Brazilian government as a strategy to increase assistance to children aged from 0 to 3 . This program is tightly related to the guidelines provided by multilateral organizations such as UNESCO and UNICEF, ratified in the various forums that bring together leaders of Latin America and the Caribbean (OAS, OEI). The Brazilian program is based on a number of ideas and recommendations aimed directly at families who become mediators in children education. This program seeks to establish new standards of conduct, disseminating practices and socializing strategies to poor families, transforming the family environment into a pedagogically oriented space. Poverty reduction is also pursued, as well as

\footnotetext{
* Professora do Curso de Pedagogia e do Programa de Pós-Graduação em Educação da Universidade do Sul de Santa Catarina (Unisul), Santa Catarina, Brasil.rosania.campos@unisul.br

** Professora do Departamento de Metodologia de Ensino e do Programa de Pós-Graduação em Educação da Universidade Federal de Santa Catarina (UFSC), Santa Catarina, Brasil. roselane@ced.ufsc.br
} 
the promotion of a favorable environment for family education, seen as essential for children's later educational success.

Key words: childhood education; educational policies; education of families.

A educação das crianças pequenas, no Brasil identificada como educação infantil, vem experimentando uma crescente visibilidade nas agendas políticas regionais e nacionais. Como exemplos dessa atenção, podemos citar o recente Relatório de Monitoramento Global de Educação para Todos (EPT), coordenado pela Unesco, intitulado "Bases sólidas: educação e cuidados na primeira infância" e a V Reunião de Ministros de Educação dos Estados-Membros da OEA que, reunidos entre 15 e 16/06/2007, firmaram intenções consubstanciadas no Documento "Compromisso Hemisférico com a Educação da Primeira Infância”. No Brasil, a inclusão recente da educação infantil no Fundeb - Fundo de Manutenção e Desenvolvimento da Educação Básica e de Valorização dos Profissionais da Educação, a criação dos programas Proinfância e Proinfantil, além dos objetivos e metas explicitados no Plano Nacional de Educação tanto são efeitos, ainda que de forma restrita, das demandas e pressões sociais por mais acesso a esse nível educativo, quanto expressão, em nível local, dos compromissos assumidos pelo governo brasileiro com os organismos multilaterais e/ou nos Planos e Projetos, em nível de América Latina e Caribe, dos quais é signatário.

Analisando os documentos produzidos nesses diferentes fóruns e as orientações políticas destinadas aos países da região, constatamos um movimento de crescimento na oferta da educação infantil na América Latina; contudo, observamos também que nesse processo conjugam-se fatores que, ao contrário das intenções declaradas, tendem a aprofundar a dualidade histórica constituinte da educação das crianças pequenas: cresce a tendência à inclusão das crianças de 4-6 anos nos sistemas formais de ensino; ao passo que para as crianças com idades inferiores a três anos tem se enfatizado e fomentado o desenvolvimento de programas de atenção, com predomínio da chamada "modalidade não formal" de atendimento. Além desses aspectos, os dados apresentados nesses documentos evidenciam que a prioridade dos governos locais tem sido a expansão e a universalização do atendimento das faixas etárias mais próximas da escolarização, motivo pelo qual se alertam os governantes para as precárias taxas de atendimento para as idades de 0 - 3 anos (Unesco, 2007; OEA, 2007; Orealc/Unesco, 2004a; 2004b).

No Brasil, a situação não parece divergir muito do cenário regional: os dados coletados pelo IBGE na Pesquisa Nacional por Amostra de Domicílio PNAD/2006 já evidenciam a configuração dessa tendência: da população estimada entre $0-3$ anos, apenas $15,5 \%$ freqüentam alguma instituição educativa; 
ao contrário, já o percentual relacionado à pré-escola não apenas apresenta indicador quase cinco vezes superior, como também foi a modalidade da educação básica com o maior crescimento em dois anos: passou de 70,5\% para $76 \%$, superando o crescimento de todas as demais modalidades da educação básica. Quando observamos a oferta de vagas por dependência administrativa, constatamos que os indicadores mais desfavoráveis se encontram também entre as creches: apenas $57,7 \%$ das crianças de $0-3$ frequientam alguma instituição pública; contrariamente, na pré-escola esse percentual é de 73,5\%.

Vale registrar ainda que as indicaçóes dos organismos multilaterais sustentam-se no pressuposto de que a educação é o principal mecanismo de combate à pobreza, constituindo-se por esse motivo também na principal alavanca para a equidade social. A educação das crianças pequenas é tratada em termos de seu potencial futuro: considerada como base para trajetórias escolares exitosas, é salientado seu caráter preventivo, sendo associada às taxas de retorno econômico - qualificação, inserção no mercado de trabalho e salários, afastando dos ciclos de pobreza aqueles que nele estão inseridos (OEA, 2007).

A ênfase a políticas de caráter compensatório não é novidade; o que parece estar mudando, como procuramos mostrar ao longo deste artigo, é que, ao contrário dos anos de 1970 e 1980, em que as crianças pobres e, em especial suas famílias, eram tomadas em sua negatividade, agora são reafirmadas em sua positividade: em aparente ruptura com representações que associavam pobreza com carência ou marginalidade cultural, trata-se agora de reforçar, de fomentar e de desenvolver seu potencial como unidade educadora.

Ponto de injunçãao de diversos discursos, as famílias pobres têm se tornado, cada vez mais, objeto de intervenção do Estado, convertendo-se em importante agente na implementação de ações deste. Ao seu potencial educativo somase o seu potencial econômico: ao tornarem-se lócus de programas de atenção voltados ao desenvolvimento das crianças pequenas, tornam-se executoras de programas governamentais e/ou programas patrocinados pelos organismos multilaterais, tais como Unicef e Unesco, reduzindo-se significativamente os custos financeiros dos mesmos.

Diante desse contexto, observamos, na América Latina, uma intensificação no fomento e na divulgação de experiências e/ou programas centrados na participação das famílias, sejam estes patrocinados por organismos que aqui atuam ou pelos governos locais. No caso brasileiro, destacamos dois programas desse tipo: um adotado nacionalmente - o Programa Família Brasileira Fortalecida ${ }^{1}$; outro, em nível estadual, criado e implementado pelo governo do Rio Grande

1. O Programa Família Brasileira Fortalecida foi implementado em 2005, em versão piloto, nos estados do Piauí, Paraíba e Ceará. Passou em 2006 a integrar os conteúdos de formação do Proinfantil, programa destinado à formação de professores leigos em serviço. 
do Sul - o Programa Primeira Infância Melhor - PIM —, cuja repercussão tende a espalhar-se por outros estados da federação. Ambos os programas, patrocinados pelo Unicef, têm como base comum o baixo custo, tendo como alvo tanto as crianças como suas famílias: no caso das crianças, adota-se uma perspectiva neurológica de desenvolvimento, visando o potencializar as competências necessárias a sua educabilidade. Já com relação às famílias, aposta-se na sua condição de educadores primeiros, procurando-se amenizar, por essa via, o grave problema de garantia de atendimento público ao direito das crianças pequenas, em especial aquelas entre $0-3$ anos, à educação.

Neste artigo, propomos apresentar uma análise do Programa Família Brasileira Fortalecida, abordando de forma mais específica as concepçôes que orientam os livretos de instruções destinados à educação das famílias no cuidado de seus filhos. Partimos do pressuposto de que esse Programa, sustentado por um conjunto de recomendações para a promoção do desenvolvimento das crianças, pretende, de fato, administrar e disciplinar as práticas de socialização das famílias pobres, transformando-as em espaços pedagogicamente orientados. Nesse sentido, poderíamos falar na emergência de novas práticas de higienização social sustentadas por dois mecanismos: a) "administração da pobreza" (Oliveira, 2000), cujo objetivo é a diminuição das disparidades sociais, processo este em que as mulheres desempenham papel importante no controle das doenças infantis de caráter epidêmico e na conseqüente redução das taxas de mortalida$\mathrm{de}^{2}$; e b) promoção de um ambiente de educabilidade familiar, considerado como essencial para o posterior sucesso escolar da criança. Neste trabalho, aternos-emos apenas ao segundo aspecto.

Para auxiliar na análise documental, recorremos às contribuições de Fairclough (2001). Consideramos importante, na análise de documentos de política educacional, atenção especial aos discursos que ali são veiculados, pois partilhamos dos supostos do autor de que

o discurso contribui para a constituição de todas as dimensões da estrutura social que, direta ou indiretamente, o moldam e o restringem $[. .$.$] . O discurso é uma prática, não apenas de repre-$ sentação do mundo, mas de significação do mundo, constituindo e construindo o mundo em significado (Fairclough, 2001, p. 91).

2. Segundo o documento "Síntese Regional de Indicadores da Primeira Infância"(Orealc/Unesco, 2004), estudos têm "comprovado que o nível educativo das mulheres é um elemento chave para o desenvolvimento infantil e tem direta incidência no nascimento e desenvolvimento das crianças. Para tanto, a educação dos pais, das famílias e das comunidades contribuem enormemente com o desenvolvimento integral dos meninos e das meninas"(tradução livre). 
Assim, nessa perspectiva, interessa-nos, na análise dos discursos presentes nos documentos de política, identificar os conceitos que difundem os seus processos de re-significação, posto ser esta uma das mais eficazes operações discursivas presentes nos discursos da política.

Compreendemos os discursos também como prática política, terreno em que os significados e sentidos das palavras entram em disputa, posto que operações discursivas particulares tendem a naturalizar relações de poder e ideologias. Conforme Shiroma, Campos e Garcia (2005, p. 432)

as disputas impregnam os textos das condiçōes e intençōes políticas que marcaram sua produção, expressando interesses litigantes [...]. Todavia, ainda conforme as autoras, as intençôes políticas imiscuídas nos discursos contêm "ambigüidades, contradiçōes e omissões que fornecem oportunidades particulares para serem debatidas no processo de sua implementação.

É dessa perspectiva, então, que inscrevemos nosso propósito de análise dos livretos de instrução que compõem o Programa Família Brasileira Fortalecida, considerado, nesse contexto de análise, como parte constituinte da política educacional para a educação infantil.

\section{A educação das famílias como política educacional - as indicações dos organismos internacionais}

A adesão do governo brasileiro a programas sócio-educativos de caráter compensatório, como o Programa Família Brasileira Fortalecida, requer ser compreendida a partir dos novos marcos regulatórios constituídos nas reformas dos estados nacionais que, inspirados em princípios neoliberais, estabeleceram novos preceitos para a administração da esfera pública. A reforma do estado brasileiro teve seus lineamentos definidos no documento intitulado Plano Diretor da Reforma do Aparelho do Estado, de 1995, na gestão do então ministro Bresser Pereira. Segundo consta neste documento, era preciso dar um "salto" em termos de administração pública, adotando-se um novo paradigma gerencial "baseado em conceitos atuais de administração e eficiência, voltada para o controle dos resultados e descentralizada para poder chegar ao cidadão" (p. 1). Nessa perspectiva, o Estado "deixa de ser responsável direto pelo desenvolvimento econômico e social pela via da produção de bens e serviços, para fortalecer-se na função de promotor e regulador desse desenvolvimento" (p. 4).

Nesse contexto de reforma, a educação passou a ser considerada como "atividade não-exclusiva" em seu provimento por parte do Estado, podendo a prestação do "serviço educacional" ser transferida para a esfera privada, em especial 
para as chamadas "organizações sociais", definidas como "públicas não-estatais". Passou, então, a ser compreendida não mais como um direito público, mas como um serviço prestado a "cidadãos-clientes", a quem caberia o controle direto sobre o fornecimento deste. Em síntese, o new public manegement visa, sobretudo, a eficiência dos serviços via estabelecimentos de mecanismos de controle, tais como a avaliação e a responsabilização (accountability) dos "atores sociais" envolvidos em seus resultados. ${ }^{3}$

No rastro da reforma gerencial do Estado, a educação também foi "remodelada". A partir da década de 1990, em convergência ainda com orientações advindas das chamadas organizações multilaterais, essa reforma resultou em mudanças que atingiram todo o sistema educacional: a gestão, o financiamento, os currículos, a implementação de sistemas de avaliação e a formação de professores foram reorientados a partir de preceitos como produtividade e eficiência, intrínsecos à gestão gerencial, afetando profundamente as práticas educativas no Brasil.

No caso da educação infantil, os impactos da reforma foram paradoxais: por um lado, constatamos avanços, em especial por sua inclusão na educação básica; por outro, a focalização no ensino fundamental associada à falta de financiamento público para creches e pré-escolas resultou, entre outros aspectos, no fomento à proliferação de programas não formais de atendimento à infância, em especial, no que tange ao atendimento de $0-3$ anos. Como resultado, constatamos que o reconhecimento do direito das crianças pequenas à educação não se tem traduzido em direito para todas; aliás, para a grande maioria trata-se ainda de um "quase-direito".

Rosemberg (2002) também destaca o crescimento de programas não formais voltados à educação das crianças pequenas no Brasil, ressaltando em especial as influências do Banco Mundial (BM) nesse nível educativo. Segundo a autora, os recursos do BM para educação infantil na América Latina priorizaram duas linhas de ação: uma para o atendimento ao pré-escolar, associado ao ensino fundamental, de caráter preparatório à escolaridade obrigatória; e outra, destinada à educação das crianças pequenas,

geralmente denominada Desenvolvimento Infantil (DI), expressão que tanto pode significar uma ampliação do enfoque para saúde, nutrição, além de educação, quanto pode significar o privilegiamento de modelos "não formais" de atendimento à criança pequena (Rosemberg, 2002, p.45).

3. Já dispomos no campo educacional de número significativo de estudos tratando da reforma do Estado brasileiro e dos impactos desta em termos da política educacional dos anos de 1990, de modo que não nos ateremos nessa discussão, posto não ser este o propósito desse trabalho (Anderson, 2007; Afonso, 200 I; Dourado, 2002). 
A autora ainda nos alerta para a presença de conceitos distintos, referindose à educação de crianças pequenas: para os países desenvolvidos, reserva-se o termo educação infantil; ao passo que para aqueles considerados subdesenvolvidos, alude-se a "desenvolvimento infantil"; termo este que, dadas sua amplitude e polissemia, pode significar formas precarizadas de atendimento à infância, na medida em que não se vincula necessariamente aos modelos formais de intervenção.

O privilegiamento dessa segunda linha de ação pelo Banco Mundial repercutiu tanto na indução de programas para a América Latina e Caribe, como também influenciou as orientaçóes de outros organismos, tais como a Unesco e a Unicef. Além dos programas e orientaçōes dos organismos citados, destacamos ainda, como marcos importantes, a Conferência Mundial de Educação para Todos (1990); a X Cumbre Iberoamericana de Jefes de Estados y de Gobierno de los Paises Iberoamericanos, coordenada pela OEI em 2000, centrada no tema "Unidos por la Niñez y la Adolescencia, Base de la Justicia y la Equidad en el Nuevo Milenio"; a X Conferência Iberoamericana de Educação que reuniu ministros da educação, também no âmbito da OEI, ocasião em que foi aprovada a Declaração do Panamá, intitulada "La Educación Inicial en el Siglo XXI". Este último documento, reportando-se aos compromissos dos governos locais com a comunidade internacional, ressalta as dificuldades da região em atingir as metas pretendidas e acordadas, fato este a requerer maior impulso dos governantes locais. Mais recentemente, a V Reunião de Ministros de Educação, dos países pertencentes à OEA (Organização dos Estados Americanos), também reconheceu as discrepâncias entre a "oferta e demanda" de educação infantil na região, sublinhando, em especial, a carência de serviços para crianças menores de três anos (OEA, 2007).

Como ponto de convergência entre as orientações desses diferentes organismos, encontramos tanto a ênfase aos programas não-formais de atendimento, como a centralidade das famílias na sua execução. Exemplifica esse encaminhamento a Declaração dos Ministros, sintetizada no documento final da X Conferência Iberoamericana de Educação: "Reconhecemos às famílias o seu papel de espaço educativo primordial, primeiro e insubstituível, e assumimos o compromisso de promover ações que tendam a seu fortalecimento e à formação dos pais e mães como agentes educadores responsáveis" (OEI, 2000, grifos nossos).

Relembramos, aqui, que essas reuniōes e convençôes regionais ratificam indicações da Conferência Mundial sobre Educação para Todos, de Jomtien (1990), reafirmadas posteriormente no Fórum Mundial de Educação, de Dakar (2001). Por considerarmos a Declaração da Conferência Mundial como um "documento fundador", ou seja, um documento a partir do qual "redes conceituais" foram construídas, retomamos aqui aspectos que nos possibilitam localizar, na 
década de 1990, as indicações que colocam as famílias e a sua educação como um elemento de política educacional.

Na Declaração da Conferência Mundial reitera-se que "a aprendizagem começa com o nascimento", salientando-se que os cuidados básicos e a educação inicial na infância devem ser "proporcionados seja por meio de estratégias que envolvam as familias e comunidades ou programas institucionais, como for mais apropriado" (sem grifos no original). Reafirma-se a importância de "propiciar um ambiente adequado à aprendizagem", destacando que "a educação das crianças e a de seus pais ou responsáveis respaldam-se mutuamente, e esta interação deve ser usada para criar, em benefício de todos, um ambiente de aprendizado onde haja calor humano e vibração" (Unesco, 1990, grifos nossos).

Dentre as metas estabelecidas, a serem assimiladas localmente pelos governos signatários da conferência, destacamos aquela voltada para a educação de crianças pequenas: "Expansão dos cuidados básicos e atividades de desenvolvimento infantil, incluídas aí as intervenções da família e da comunidade, direcionadas especificamente às crianças pobres, desassistidas e portadoras de deficiências" (Unesco, 1990).

Encontramos, na Declaração da Conferência Mundial, o principal fundamento que orientará outros documentos de organismos como Unesco, Cepal e Unicef para a educação infantil: a educação da primeira infância como précondição para a qualidade, equidade e eficácia da educação (Unesco, 1990). Dessa perspectiva, a educação infantil é tratada como oportunidade (e não direito) de desenvolvimento para a criança, e pré-requisito à eficácia dos sistemas educacionais, em especial, no que tange aos processos de escolarização posteriores.

Também no Plano de Ação, documento de orientação à implementação de planos nacionais para se atingirem as metas acordadas, reitera-se o importante papel a ser desempenhado pelas famílias. No artigo 7 (Fortalecer as alianças), argumenta-se que a responsabilidade pelo provimento da educação precisa ser compartilhada entre os governantes e demais segmentos sociais, enfatizando-se a força e a necessidade das alianças com setores comunitários e famílias. Com relação a estas últimas, ressalta-se que é "particularmente importante reconhecer o papel vital dos educadores e das famílias".

Em documento produzido pela Orealc/Unesco (2004), intitulado "Síntese Regional de Indicadores da Primeira Infância", centrado na apresentação de indicadores de qualidade da educação infantil na América Latina, reforça-se também a idéia da "educação da família" como estratégia para provimento não formal da educação infantil. Conforme o documento:

no marco das políticas existe um reconhecimento universal a respeito dos pais como os principais educadores de seus filhos e 
que sua participação e formação são essenciais para o adequado desenvolvimento destes e uma melhor relação com eles [filhos] (Unesco/Orealc, 2004, p. 20).

Destaca também uma tendência da região, América Latina e Caribe

de incluir a educação e orientação dos pais dentro da educação inicial, de modo que recebam a informação necessária para cuidar de seus filhos e aprendam as atividades de estimulação adequadas para eles. Por isso, a educação dos pais e mães ou famílias raras vezes é abordada como um tema independente em termos de seu próprio desenvolvimento e formação (Unesco/Orealc, 2004, p. 20, tradução livre e grifos nossos).

Seguindo essa lógica, os programas nacionais voltados para a educação de pais são destacados como exemplos e difundidos como experiências inovadoras que estão alcançando bons resultados. Fazem parte das recomendaçóes: a formação de pais; os programas para docentes sobre o trabalho com os pais; a formação de mães da comunidade para que executem programas de atenção às crianças; as campanhas massivas de informação, sensibilização e participação dos pais nos processos educativos em aula, na elaboração dos projetos educativos e institucionais; e a gestão de recursos.

A expansão de programas centrados na família é reiterada, também, no documento Participación de las Famílias en la Educación Infantil Latinoamericana, produzido pela Unesco, em 2004. Neste documento, destinado a um balanço das experiências em curso na região, tal como nos demais já mencionados, também se reafirma a correlação positiva entre a ambiência familiar e o desenvolvimento escolar ulterior. A diversidade de experiências na região é ressaltada, mencionando-se, no entanto, que nem sempre se concebem "os pais e mães como atores individuais e sociais", com participação ativa no desenho e na gestão dos programas; na maioria das vezes, estes são apenas receptores passivos.

Como podemos observar pela breve análise dos documentos aqui apresentados, a adoção do Programa Família Brasileira Fortalecida pelo governo brasileiro como um elemento de política educacional não é fato isolado. Mantém estreita vinculação com programas semelhantes desenvolvidos em outros países da região, podendo ser compreendido como expressão local da "agenda global", no sentido proposto por Dale (2001). Essa articulação entre os diferentes "locais", exemplificada pela difusão das experiências ditas "exemplares" ("boas experiências" ou "experiências exitosas"), produz também um sentido de generalidade, de universalidade; e, por esse movimento, procura dotar de legitimidade as ações de política educacional, apagando, assim, a ideologia que as informa. Como afirma Fairclough (2001, p. 117), “as ideologias embutidas nas 
práticas discursivas são muito mais eficazes quando se tornam naturalizadas e atingem o status de 'senso comum".

\section{A educação das famílias como estratégia para a educabilidade das crianças pequenas}

O Programa Família Brasileira Fortalecida é apresentado como uma parceria entre governo brasileiro, Unicef e organizaçóes da sociedade civil, sendo o seu objetivo o desenvolvimento de competências familiares com vistas ao desenvolvimento integral de meninas e meninos. Embora, na apresentação do documento, anuncie-se a intenção de "fortalecer as famílias sob o enfoque dos direitos", tal parecer não se realiza, pois, como veremos a seguir, trata, sobretudo, de prescrever comportamentos e atitudes esperadas dos pais, a partir de preceitos oriundos dos campos da psicologia e da medicina.

O Programa tem como objetivo formar educadores - agentes comunitários de saúde, professores, líderes comunitários - para intervirem nas famílias, difundindo os conteúdos veiculados em cada livreto que compõe o kit de formação. Compõem esse kit cinco livretos (designados como "álbuns"), cada qual destinado a uma etapa do desenvolvimento da criança, exceto o primeiro, dedicado aos cuidados de saúde que antecedem o nascimento da criança. Assim, temos: álbum $1^{\circ}$ : pré-natal, parto e pós-parto; $2^{\circ}$ : o primeiro mês de vida; $3^{\circ}$ : a criança do $2^{\circ}$ ao $12^{\circ}$ mês de vida; $4^{\circ}$ : a criança de $1-3$ anos; $5^{\circ}$ : a criança de 4-6 anos. Cada álbum destes é composto de pequenos módulos, abordando um tema ou aspecto de desenvolvimento específico. Neste trabalho, dado o seu escopo, analisaremos apenas o álbum 4, destinado às crianças de 1-3 anos.

Chama-nos a atenção a estrutura dos álbuns referenciados. Apresentam uma "arquitetura textual" articulada a partir de diferentes elementos - textos escritos, com diferentes tipos de letras, fundo colorido, imagens ilustrativas, pequenos boxes, rodapés destacados - que servem para compor uma imagem de "texto dinâmico" e ágil em suas formas de comunicação. Isso é reforçado pela linguagem utilizada, bastante simplificada e direta, sugerindo um tom de intimidade com seus interlocutores (agentes educadores e famílias). Todavia, a análise de sua "gramática" alerta-nos para o tom prescritivo e normativo que os acompanha, em especial naquele que analisamos: a presença predominante dos verbos "precisar" e "dever".

A força argumentativa dos textos parece residir justamente nessa combinação de prescrição e de aconselhamento e, sobretudo, na legitimidade que o discurso científico the empresta, produzindo um sentido de irrefutabilidade por parte daqueles aos quais se destina. A naturalização de situaçôes de vida e 
de processos históricos processa-se pela presença de frases em pequenos boxes destacados no início de cada módulo. Essas frases que assumem a forma de conselhos e, portanto, revelam premissas morais, tematizam aspectos da vida cotidiana, assumindo também um tom de "auto-ajuda". Encontramos frases tais como:

\author{
"Organize o futuro, o tempo já passou", \\ "Nada conseguimos na vida sem perseverança", \\ "Plante as sementes da bondade do amor por onde quer que \\ você passe", \\ "Todo homem é criativo, é necessário que o saiba", \\ "Não roube as idéias dos outros, empregue-as construtivamente".
}

O caráter moralizador presente no texto é também reforçado pelas imagens de famílias apresentadas como ilustrações dos textos: são representações idealizadas da família nuclear moderna, de interações entre pais e filhos em situações de brincadeiras, de jogos e de leitura (módulos sobre desenvolvimento psicológico). Interessante assinalar que essas imagens privilegiam cenas com livros, materiais escolares ou jogos educativos, reafirmando, desse modo, um dos objetivos que orienta este Programa - a preparação para processos escolares exitosos. Visa-se à educabilidade das crianças pequenas como condição para o êxito escolar, educabilidade esta a ser construída nos processos ditos de socialização primária, que têm lugar no interior das famílias. De acordo com Tedesco (2002, p. 9), a noção de educabilidade é uma construção social

\begin{abstract}
que transcende ao sujeito e sua família e que dá conta do desenvolvimento cognitivo básico que se produz nos primeiros anos de vida - vinculado a uma adequada estimulação afetiva, boa alimentação e saúde - e a socialização primária mediante a qual as crianças adquirem os rudimentos de um marco básico que os permite incorporar-se a uma situação distinta da família, como é a escola.
\end{abstract}

Ainda segundo o autor, toda criança nasce "potencialmente educável", porém nem sempre o contexto social favorece o desenvolvimento dessa potencialidade, motivo pelo qual as famílias devem, desde o nascimento, criar condiçōes para que as crianças desenvolvam disposiçōes e atitudes "que conformam a base que condiciona e torna possível as aprendizagens posteriores" (Tedesco, 2002, p. 11).

$\mathrm{Na}$ perspectiva da educabilidade, as lógicas socializadoras das famílias devem ser objeto de intervenção, atuando-se no sentido de aproximá-las daquelas inerentes ao "modo escolar de socialização"; "visa-se, nesse sentido, a uma 'pedagogização' das relaçôes sociais de aprendizagem" (Thin, 1998, p. 27). 
Essa pedagogização expressa-se ainda no formato "didático" dos álbuns, aproximando-se do formato dos manuais de orientação. As caracterizaçōes ou explicações acerca do desenvolvimento da criança buscam fornecer informaçôes de caráter "científico", posto que se apóiam em teorias psicológicas (embora não haja qualquer alusão a estas); já as recomendaçōes são apresentadas como respostas a perguntas, abordando o "como se deve proceder" com a criança em diferentes situaçōes de interação. Nesses casos, encontramos, ainda, pequenos lembretes, tais como "Cuidado", ou "Atenção" que, dado seu tom de alerta, destacam de modo privilegiado as informaçôes fornecidas.

Enfim, a educação das famílias como estratégia para disciplinarização da pobreza não é fato novo. Não se trata, obviamente, de postular uma recapitulação da história, mas, considerando que o presente mantém nexos com o passado, a retomada de iniciativas dessa natureza, em que pese a particularidade do momento histórico em que se inscreve, mantém e reatualiza elementos dos discursos médico-higienistas do começo do século XIX. Como destaca Gondra (2002 p. 290), os tais discursos médico-higienistas, no que se refere à infância, organizam-se em formas de "procedimentos, cujo início se daria no controle das condutas anteriores dos pais, estendendo-se até a 'idade dos colégios', demarcando fronteiras e instituindo empréstimos entre o espaço da casa e o da escola". Estaríamos diante de um novo modelo de "assistência científica" que, conforme assinalado por Kuhlmann Jr. (1998), defende uma educação mais moral do que intelectual e objetiva mais a atuação sobre cada criança individualmente, não fazendo referência à coletividade?

A deslegitimação das competências das famílias pobres para educar seus filhos parece ser o ponto de partida deste Programa. As ações propostas parecem caminhar no sentido da transformação de seus modos de relação com os filhos, em função de modelos socializadores supostamente mais eficientes e promissores no que tange ao futuro escolar das crianças. Não se questiona aqui a incapacidade histórica da escola em atuar com as chamadas classes populares, transferindo para estas últimas a responsabilidade pela insuficiência ou incapacidade de garantir a formação das chamadas disposições e atitudes para a educabilidade.

\section{Desenvolvimento e educabilidade da criança - da criança real à criança representada}

A idéia de educabilidade e, portanto, do desenvolvimento de disposições e atitudes cognitivas, afetivas, sociais das crianças ou, de outro modo dizendo, de tornar a criança educável, apóia-se, por sua vez, em supostos que têm como referência a universalidade do desenvolvimento infantil. Essa também é a pers- 
pectiva que ancora as concepções difundidas nos materiais do Programa aqui analisado.

No álbum 4, essa concepção naturalizada de desenvolvimento orienta as informações relacionadas às aquisiçôes sócio-cognitivas da criança. Estas são apresentadas a partir de breves caracterizaçóes comportamentais, classificadas por áreas e idades, reproduzindo a já tão criticada "psicologia normativa". A estas informações, seguem-se recomendaçôes sobre como atuar com a criança. Sacristán (2005, p. 47) alerta para os riscos das periodizações normativas em termos de desenvolvimento infantil. Segundo o autor, com esse procedimento termina-se por naturalizar o devir do ser, posto que a partir do conhecimento psicológico pretende-se regular e guiar o devir do sujeito, naturalizando também o dever ser e, em suma, também sua educação. Conforme o autor,

Ao nos oferecer uma idéia determinada da criança ou do adolescente, não só se descrevem e explicam fatos ou estágios, mas também se formula o que podemos esperar que o sujeito seja em um momento de seu desenvolvimento; isto é, nos proporcionam metas normativas a alcançar e normas ou níveis para graduar e "rotular" os indivíduos (Sacristán, 2005 p. 47).

Essa forma de tratar o desenvolvimento da criança desconsidera que ele ocorre em contextos socioculturais concretos, orientado por necessidades historicamente construídas. Ao contrário dessa direção, predominante nos estudos atuais da educação infantil, a perspectiva adotada nos materiais analisados, ao sustentar a idéia da criança como um "organismo em formação, que se desenvolve por etapas, segundo uma dada cronologia" (Jobim e Souza, 1996 p. 45), reforça também explicações simplistas e lineares sobre a relação entre a atividade infantil e as bases biológicas do seu desenvolvimento. Exemplo dessa simplificação encontramos no Álbum 4: "quanto mais a criança é estimulada a falar, movimentar-se e descobrir, maior será o desenvolvimento do seu cérebro e da coordenação fina de seus movimentos" (Álbum 4, Unicef).

Ao veicular esse tipo de informação, sustenta-se a idéia de que o desenvolvimento é uma evolução progressiva e em etapas das capacidades da criança (Jobim e Souza, 1996). A infância aqui é tomada como um dado universal, como uma categoria natural que é descrita em seus traços essenciais, porém desenraizada do contexto social em que a criança concreta vive (Almeida, 2000, p. 26).

$\mathrm{O}$ tom moralista empregado no tratamento às famílias repete-se também quando se trata das crianças; sob a chamada de "Atenção", lemos: "a criança já entende o que falam com ela, mas nem sempre obedece. Ela atende quando se interessa por fazer o que foi pedido; e chora e faz pirraça quando é contrariada" (Álbum 4, Unicef). 
Emerge, nessa afirmação, a representação de uma criança "caprichosa", invocando também, de forma complementar, uma idéia de educação fundada sobre a rejeição da espontaneidade, como meio para domesticar os caprichos, visando à obediência. Relembramos aqui o destaque feito por Kuhlmann (1998), ao analisar a educação do século XIX, cujo objetivo era integrar rapidamente "os pequenos à sociedade, treinando os pais, a mãe, a seguir apenas as prescriçôes indicadas como as necessárias para o bom desenvolvimento da infância” (p.192).

As brincadeiras infantis são consideradas como importantes atividades, sendo destacadas em módulo próprio. Aqui também encontramos afirmações que reafirmam crenças do senso comum, como por exemplo: "a criança acha que é o centro do mundo e tem dificuldade de compartilhar", ou então: "ao brincar, a criança desenvolve a atenção, imitação, memória, movimentação, equilíbrio e imaginação. Também constrói curiosidade, confiança e auto-estima" (Álbum 4, Unicef)

Essa simplificação da brincadeira está imbuída da idéia de que esta é uma atividade inerente à criança, isto é, de natureza instintiva. Descaracteriza-a como uma atividade precisamente humana, cultural, ou seja, como "atividade objetiva que, por constituir a base da percepção que a criança tem do mundo dos objetos humanos, determina o conteúdo de suas brincadeiras." (Leontiev, 1998, p. 120).Essa naturalização segue nas indicações do que a criança gosta de fazer e de brincar: "bater palmas quando está contente", "virar as páginas dos livros sem rasgar", "querer tudo para si e quando ouve um não, chora e faz pirraça". Mencionam-se também os objetos com os quais as crianças gostam de brincar: "com caixas vazias de tamanhos variados", "com embalagens vazias e limpas, transformadas em brinquedos". Observamos aqui a analogia entre os objetos sugeridos como brinquedos e a sua frequiente utilização para a elaboração de "brinquedos de sucata".

\section{Considerações finais}

As análises que apresentamos pretenderam problematizar o Programa Família Brasileira Fortalecida, as concepções e os propósitos que o orientam. Se registramos, por um lado, avanços importantes do atual governo no que tange à intenção de construção de uma política para a educação infantil, por outro lado, iniciativas dessa natureza parecem caminhar na contramão dessa mesma política, quer por seu caráter compensatório e pontual, quer pelas concepçōes que ali são difundidas. Reafirmamos, com Faria (2005, p. 1031), a necessidade de combater os "programas episódicos, que pulverizam os recursos e não estão voltados para uma política articulada, enraizada na diversidade cultural brasileira". 
É dessa perspectiva que consideramos também que o direito da criança ao seu pleno desenvolvimento não admite como condicionalidade a busca de eficácia dos sistemas educacionais, eficácia esta representada apenas em estatísticas e indicadores, e não em efetividade social para as crianças. A educabilidade e a administração da pobreza, traduzida nos atuais discursos sobre a equidade de oportunidades, constituem-se nos principais eixos de programas dessa natureza que retomam e reforçam idéias, já largamente combatidas no campo da educação; em especial, a idéia da moralização e da disciplinarização das classes pobres.

Lembramos que os álbuns, escritos na forma de pequenos manuais, além de orientarem o atendimento da criança, também se apresentam como uma forma de institucionalizar uma determinada ordem de organização familiar. E, nesse contexto, a educação traduz-se como estratégia fundamental para operar as transformações sociais e culturais de que o novo modo de organizaçăo econômica necessita (Ferreira, 2000).

Todavia, os documentos, assim como a política educacional, são eivados de contradiçōes; e trazem em seu próprio bojo as tensōes resultantes das forças sociais que se econtram em lítigios. Desse modo, retomamos as palavras de Rocha (2002, p. 75), para quem a desigualdade social torna insustentável a condição de vida das famílias, motivo pelo qual os governantes são impelidos à "criação de programas e instituiçõos que exerçam uma ação paralela e até substituta de educação da criança para submeter as novas gerações aos padrões morais e até sanitários considerados necessários para o desenvolvimento" (Rocha, 2002 p. 75).

Como resultado dessa análise, observamos que as indicações e propostas que incentivam o "protagonismo" das famílias não se pautam na idéia da participação como ação coletiva ? envolvendo profissionais, pais e crianças, a partir de diálogos educativos, e da reciprocidade entre família e instituição ?, na perspectiva da gestão democrática, tal como assegura, no Brasil, a Lei de Diretrizes e Bases da Educação Nacional (Lei 9394/96). Ao contrário, as indicações tendem a enfatizar o protagonismo da família em duas direções: a) como provedoras de educação, quando executam programas governamentais cujo alvo é o atendimento das crianças pequenas; b) como receptoras de educação ou de informaçôes, quando são alvo de programas que visam à sua sociabilidade. As famílias são tomadas como "parceiras" ou "sócias" (OEA, 2007) no partilhamento da oferta dos serviços educacionais; em ambas as situações é atribuído às famílias o importante papel de mediadores sociais, acreditando-se no potencial educativo delas como meio para amenizar ou garantir as condições necessárias ao pleno desenvolvimento das crianças. 
Em síntese, as indicaçōes presentes nesses programas pautam-se na lógica de restrição de participação dos Estados como responsáveis pelo provimento do direito à educação básica, em especial, da educação infantil. Dividem e transferem responsabilidades no provimento desse direito a outros sujeitos coletivos, dentre os quais, como já mostramos, as famílias. Registre-se ainda, como bem observa Rosemberg (2002), que programas dessa natureza criam, recriam e sustentam-se na subordinação de gênero. As mulheres são o foco da intervenção; sua educação é considerada necessária para diminuir as taxas de desnutrição, mortalidade infantil e elevar o aproveitamento escolar de seus filhos. Paradoxalmente, os mesmos organismos que incentivam programas dessa natureza também fomentam metas e objetivos para incentivar a igualdade de gêneros.

\section{Referências bibliográficas}

AFONSO, Almerindo J. Reforma do Estado e políticas educacionais: entre crise do EstadoNação e a emergência da regulação supranacional. Educação e Sociedade, Campinas, v. 22, n. 75, ago. 2001.

ALMEIDA, Ana Nunes. A sociologia e a descoberta da infância: contextos e saberes. In: Fórum Sociológico: Instituto de Estudos e Divulgação Sociológica, n.3/4., 2000. Lisboa: Faculdade de Ciências Sociais e Humanas, Universidade de Lisboa, 2000.

ANDERSON, Perry. Balanço do neoliberalismo. In: SADER, Emir; GENTILI, Pablo (Org.). Pós-neoliberalismo: as políticas sociais e o Estado democrático. 7. ed. Rio de Janeiro: Paz e Terra, 2007.

BRASIL. PRESIDÊNCIA DA REPÚBLICA. CÂMARA DE REFORMA DO ESTADO. Plano Diretor da Reforma do Aparelho do Estado. Brasília: novembro, 1995.

BRASIL. Lei no 9.394196 de 20 de dezembro de 1996. Estabelece as Diretrizes e Bases da Educação Nacional. Brasília, 1996.

BRASIL. MINISTÉRIO DA EDUCAÇÃO. Programa Família Brasileira Fortalecida. Brasilia: MEC, s/d.

DALE, R. Globalização e educação: demonstrando a existência de uma "cultura educacional mundial comum" ou localizando uma "agenda globalmente estruturada para a educação"? Educação, Sociedade \& Culturas, Porto, n.16, p. 133-169, 2001.

DOURADO, L. F. Reforma do Estado e as políticas para a educação superior no Brasil nos anos 90. Educação e Sociedade, Campinas, v. 23, n 80, set. 2002.

FAIRCLOUGH, Norman. Discurso e mudança social, Brasília: Editora da UnB, 2001.

FARIA, Ana Lúcia Goulart de. Políticas de regulação, pesquisa e pedagogia na Educação Infantil, primeira etapa da Educação Básica. Educação e Sociedade, Campinas, v. 26, no 92. Especial, out. 2005. 
FERREIRA, Manuela. Salvar corpos, forjar a razão: contributo para uma análise crítica da criança e da infância como construção social em Portugal: 1880 - 1940. Lisboa: Instituto de Inovação Educacional, 2000.

GONDRA, José G. Modificar com brandura e prevenir com cautela. Racionalidade médica e higienização da infância. In: FREITAS, Marcos Cezar de; KUHLMANN Jr., Moysés (Org.). Os intelectuais na história da infância. São Paulo: Cortez, 2002.

JOBIM ESOUZA, Solange. Ressignificando a psicologia do desenvolvimento: uma contribuição crítica à pesquisa da infância. In: KRAMER, Sonia; LEITE, Maria Isabel (Org.). Infância: fios e desafios da pesquisa. Campinas, SP: Papirus, 1996.

KUHLMANN Jr., Moysés. Infância e Educação Infantil: uma abordagem histórica. Porto Alegre: Mediação, 1998.

LEONTIEV, A.N. Os princípios psicológicos da brincadeira pré-escolar. In: VYGOTSKY, L.S.; LURIA, A. R.; LEONTIEV, A. N. Linguagem, desenvolvimento e aprendizagem. São Paulo: Ícone, 1998.

OEA/CIDI. Reuniāo de Ministros da Educação, 5, 2007. Compromisso hemisférico com a educação da primeira infância. Cartagena das Índias, Colômbia, 2007. Disponível em: <www.sedi.oas.org/ dec/Vministerial/documentos /post_reunion/rme000133p02>. Acesso em: 25 jul. 2008.

OEI. Declaración de Panamá: Unidos por la niñez y la adolescencia, base de la justicia y la equidad en el nuevo milênio. Cumbre Iberoamericana de Jefes de Estado y de Gobierno de Los Países Iberoamericanos, 10, 2000. Panamá, noviembre, 2000. Disponível em: <www.oei.es/ xcumbredec.htm>. Acesso em: 15 jan. 2007.

OEI. Declaración de Panamá: La educación inicial en el siglo XXI. Conferencia Iberoamericana de Educación, 10, 2000. Ciudad de Panamá, Panamá, jul. 2000. Disponível em: <http:// www.oei.es/xcie.htm>. Acesso em: 15 jan. 2007.

OEI. Conferencia Iberoamericana de Educación, 12., 2002. Santo Domingo, República Dominicana, julio de 2002. Disponível em: <http://www.oei.es/xiicie.htm>. Acesso em: 15 jan. 2007.

OLIVEIRA, Dalila Andrade. Educação básica: gestão do trabalho e da pobreza. Petrópolis: Vozes, 2000.

OREALC/UNESCO. Sintesis Regional de Indicadores de la Primera Infancia. Santiago, Chile, 2004.

ROCHA, Eloísa Acires Candal. Infância e educação: delimitações de um campo de pesquisa. Educação, Sociedade e Cultura — Revista da Associação de Sociologia e Antropologia da Educação. Porto, Portugal, n.17.2002. Portugal.

ROSEMBERG, Fúlvia. Organizações multilaterais, estado e políticas de Educação Infantil. Cadernos de Pesquisa, São Paulo, n.115, março 2002.

SACRISTÁN, José Gimeno. O aluno como invenção. Trad. Dayse Vaz de Moraes. Porto Alegre: ArtMed, 2005. 
SHIROMA, Eneida Oto; CAMPOS, Roselane F; GARCIA, Rosalba M.C. Decifrar textos para compreender a política: subsídios teórico-metodológicos para análise de documentos. Revista Perspectiva, Florianópolis, v. 23, n. 02, p. 427-446, jul/dez, 2005.

TEDESCO, Juan Carlos; LÓPEZ, Nestor. Las condiciones de educabilidad de nos los ninôs y adolescentes en America Latina. IIPE: Buenos Aires, 2002. (versión preliminar).

THIN, D. Quartiers populaires: l'école et les familles. Presses Universitaires de Lyon: Lyon, 1998.

UNESCO. Informe de seguimiento de la EPT en el mundo: Bases sólidas: atención y educación de la primera infancia. Paris: Ediciones UNESCO, 2007. Disponível em: <http:// unesdoc.unesco.org/images/0015/001505/150518S.pdf>. Acesso em: 31 mar. 2007.

UNESCO. O marco de ação de Dakar. Educação para todos: atingindo nossos compromissos coletivos. Informe final de Dakar. Senegal, Dakar, 2000. Disponível em: $<$ http://www.unesco.cl/ medios/biblioteca/documentos/ept_dakar_informe_final_esp.pdf. Acesso em: 31 mar. 2007.

UNESCO. Declaración mundial sobre educación para todos: la satisfacción de las necesidades basicas de aprendizaje. Jomtien, Tailândia, 1990. Disponível em: <www.unesco.cl/medios/ biblioteca/documentos/ept_jomtien_declaracion_mundial.pdf >. Acesso em 31 mar. 2007.

UNESCO/OREALC. Participación de las familias en la Educación Infantil Latinoamericana. Santiago, Chile, agosto, 2004a. Disponível em: <www.unesco.cl/medios/biblioteca/ documentos/participacion_familias_educacion_infantil_latinoamericana.pdf . Acesso em: 22 jun. 2006.

UNESCO/OREALC. Sintesis regional de indicadores de la primera infancia. Santiago, Chile, mayo, 2004b. Disponível em: <http://www.unesco.cl/medios/biblioteca/documentos/ sintesis_regional_indicadores_primera_infancia.pdf>.Acesso em: 31 maio 2006.

Recebido em 19 de setembro de 2008 e aprovado em 20 de dezembro de 2008.

Pro-Posiçōes, Campinas, v. 20, n. 1 (58), p. 207-224, jan./abr. 2009 